\title{
Differences in L1 and L2 Academic Writing
}

\author{
Yingli Wang \\ Hebei United University, Hebei, China \\ Email: carol.wang.yl@gmail.com
}

\begin{abstract}
Since the first contrastive rhetoric study by Kaplan in 1966, many studies have been produced, and over several decades of development, there have been many contributions gained from previous contrastive rhetoric studies. In this article, many kinds of differences existing in L1 and L2 academic writing have been discussed. I will categorize the differences in three major parts as following: differences in the level of lexicon, differences in the level of sentence, and differences in the level of passage.
\end{abstract}

Index Terms - contrastive rhetoric, academic writing, difference between $\mathrm{L1}$ and $\mathrm{L2}$

\section{INTRODUCTION}

Robert B. Kaplan's study on the differences in discourse structures in different languages in 1966 is the beginning of the huge corpus of contrastive rhetoric studies. Then because of the development of text linguistics and discourse analysis during the 1980s (Enkvist, 1987; Leki, 1991, see Matsuda, 1997), contrastive rhetoric study began to focus on the systematic study of the organization in L1 and L2 rhetoric (Martin, 1992, see Matsuda, 1997) and to "consider whole texts as dynamic entities" (Connor, 1996, P.19). Later Connor (1996) redefines contrastive rhetoric as "an area of research in second language acquisition that identifies problems in composition encountered by second language writers and, by referring to the rhetorical strategies of the first language, attempts to explain them"(P.5). Throughout the three decades, many contributions have been made from previous contrastive rhetoric studies in various fields such as in ESL education, translation, and genre-specific writing (Connor, 1996; Noor, 2001).

Among those research and studies, one statement drew my attention particularly. Stapleton (2002) claims in his paper that the difference between academic writing in an L1 and L2 are often misrepresented and overstated. In his paper Stapleton demonstrates that except for the minor difference in genre, structure and the development of the article, there are lots of resemblances in academic writing between L1 and L2. Although Stapleton's study was persuasive enough to some audience, in my point of view he neglects the great diversity in academic writing between L1 and L2. I disagree with Stapleton's point of view. In my opinion, the differences in academic writing between L1 and L2 are not misrepresented and overstated. There are many kinds of differences existing in L1 and L2 academic writing. I will categorize the differences in three major parts as following: differences in the level of lexicon, differences in the level of sentence, and differences in the level of passage. At the level of lexicon, the differences in the formation of word and in the choice of word will be mentioned. Then at the level of sentence, the differences in the sentence patterns and in the sentence subject will be discussed. Finally at the level of passage, differences in the choice of writing topic, in the voice, in the organization, in the reader's and writer's responsibility, in the attitude toward quotation, in the attitude on good writing, and in writing conventions of discourse community will be elaborated.

\section{MAIN Differences BETWEEN ACADEMIC WRITING IN L1 AND L2}

\section{A. Differences in the Level of Lexicon}

There are some differences in academic writing between in L1 and in L2 in the level of lexicon, such as the formation of word (character), and the choice of word.

\section{Differences in the formation of word (character)}

When mentioning the academic writing, we should firstly discuss the word --- the basis of writing. The different way of word formation between L1 and L2 can result in diversity at the word, phrase, sentence and paragraph level and even the whole article itself.

XiaoPin, Ao (1997) suggested, "There are big differences between Chinese and English words" For instance, some Chinese characters can show its meaning from its grapheme. In other words people can guess the signification but can not know the pronunciations of the character from its formation structure. For instance, the Chinese character "明" (bright or brightness) which means light and brightness is made up by "日" (sun) and "月" (moon). People can figure out the meaning of "明" which is bright or brightness, because "日" (sun) and "月" (moon) can bring people brightness.

The formation of English word is different. Most English words can show their pronunciations but can not show the meaning from themselves. That is to say people can read "bright" out but can not know the exact meaning of "bright". Xiufeng, Zhao(2004) suggested that "structural difference of nominal groups between Chinese and English affect Chinese students' styles in English writing". The differences in word formation between L1 and L2 can lead to differences in sentences, and structure in academic writing. 


\section{Differences in the choice of word}

Besides, there are some differences in the choice of word. English speaking students use more nominalizations. Kachru (1983) compares Hindi and English, and finds that more pronouns are used in narratives in English than in Hindi (Noor, 2001, p.260). English language speakers prefer simple words. Therefore They would like to use nominalizations and pronouns to express meaning simply. The choice of word forms in L1 writing would be transferred into L2 writing (Kaplan, 1976, cited in Mohan \& Lo, 1985).

\section{B. Differences in the Level of Sentence}

In this part, the differences in L1 and L2 academic writing will be discussed from two aspects: the sentence pattern and the subject of a sentence.

\section{Differences in the sentence patterns}

The sentence patterns of first language will influence the second language writing (Staplan, 1976, cited in Mohan \& Lo, 1985). It shows that there do exist many differences between L1 and L2 academic writing. Arab students use many parallel sentences in their English essays. Spanish students like to use long sentences (Noor, 2001, p.257). After comparing Spanish and English, Santana-Seda (1975) claims that Spanish students use more coordinate sequences while English students use more subordinate sequences (Noor, 2001, p.258). Chinese speakers would use more short sentences compared to English speakers. When I translate an English sentence with a subordinate clause into Chinese, it will be translated into several Chinese short sentences to express the same meaning of the English sentence, because there is no subordinate clause in Chinese.

\section{Differences in the sentence subject}

In academic argument essays, Chinese speakers often use people as the subject in the sentences. They like to involve the role of people in the description of activities. Chinese believe people play a very important and active role in the process of knowing and reforming the outside world (He Shanfen, 2002, p.474).

But in English academic argument essays, in order to show what they are saying is the objective fact, English speaking people prefer to use passive tense in the sentences of which the subjects are objects. Ostler's (1988) study shows that English speaking students use more passives in their essays (Noor, 2001, p.257). This point is also supported by Pan Wenguo (1997) and He Shanfen (2002) respectively. In Pan Wenguo (1997)'s book, he provides some text examples and explains why Chinese speakers like to use people as subjects in sentences.

\section{Differences in the Level of Passage}

At the level of passage, the differences in L1 and L2 academic writing will be summarized into six categories. They are differences in the choice of writing topic, differences in voice, differences in organization, differences in reader's and writer's responsibility, differences in the attitude toward quotation, differences in the attitudes on good writing.

\section{Differences in the choice of writing topic}

The choice of writing topic is influenced by cultural background and social conditions. Choice of writing topic is one factor which reflects individual's cultural background and social context. The social and cultural background influences choice of topic in writing.

For example, in Chinese writing, people will discuss their personal beliefs because they consider them to be common and public topics. While in English writing, people seldom discuss around the topics of personal beliefs because in English speaking cultures, issues like beliefs are personal and it is not suitable to be discussed publicly. This is an example of cultural influence on choosing writing topics.

There is another example of social conditions influencing topic choice. In western society, most people advocate laws and would like to discuss issues from the perspective of law. But in Chinese society, people prefer moralization so they would like to discuss it from the perspective of morals. So Noor (2001) suggests social conditions constrain the choice of topic (p.265).

\section{Differences in voice}

Matsuda (2001) defines the notion of voice which refers to all the language characteristics shown from writing. The voice is social and cultural influenced. It is changing as time goes on (cited in Stapleton, 2002, p.178). As Elbow (1981) describes, voice is individual's written reflection of culture (cited in Stapleton, 2002, p.178).

When writing academic articles, English writers establish their claim early and directly in their articles and like expressing showing their own " voice", and show their " authorial presence" (Hyland, cited in Stapleton, 2002. p.178) and "authorial identity"(Hirvela \&Belcher; Ivanic\&Camps; Tang and John, cited in Stapleton, 2002. p.178) in their academic writing such as expository prose and argumentation genre. In contrast Chinese writers seldom use voice, authorial presences and authorial identity and they bring forward the claim much later in the article and more indirectly. Shen(1989 cited in Stapleton 2002, p. 179) explores the reasons why Chinese writers experience difficulty using their own voice, by, for example using the pronoun "I".

\section{Differences in organization}

As Kaplan (1972) says that "each language and each culture has a paragraph order unique to itself" (cited in Mohan $\&$ Lo, 1985, p.517). There are some differences in academic writing between different languages in organization aspect. 3.1 Linear and Curvy 
There is huge diversity in paragraph organization between L1 and L2 academic writing. In 1966, Kaplan suggested that western people especially English speakers "use a predominantly linear paragraph organization in expository texts". (Kaplan, cited in Noor 2001, p.256). Clyne (1980, 1981, \& 1983) studies essay writing and makes a conclusion that German writing is in a less linear way than English (Noor, 2001, p.260).

In contrast, other languages show a different, non-linear organization of paragraphs in expository prose. Arabic speaking students have elaborate introductions but less consistent conclusions. Japanese students put more details in the latter parts and these details often have less relation with the topics (cited in Noor, 2001, p.257).

Shen (1989) claims English writing is straight linear style but Chinese writing is different. In Chinese writing, students would like to start with the explanation of conditions. After clearing the surroundings, the Chinese students get to the real target (cited in Stapleton, 2002, p.181). Therefore, the Chinese approach is 'turning and turning in a widening gyre.'"(Kaplan 1966, cited in Noor 2001, p.256). In other words, Chinese people obviously produce writing in a curvy way.

\subsection{Deductive and Inductive}

Kaplan explained that "an expository discourse in English begin with a topic statement, which was followed by subdivisions supported by examples and illustrations that central idea was developed to prove or argue the subject in question, relating the central idea to all the other ideas in the whole essay." (Kaplan 1966 cited in Noor 2001, p256) "In reference to Kaplan (1966)'s seminal paper on contrastive rhetoric, Shen (1989) claimed that contrary to the "straight line Western approach" (Shen,1989, p. 463, as cited in Stapleton, 2002, p.180) of composition, Chinese writing follows the Confucian style of first starting the conditions of composition: how, why, and when the piece is being composed. All of this will serve as a proper foundation on which to build a house". (Stapleton, 2002 p.180) In other words Chinese academic writing is inductive and English writing is deductive. (Stapleton, 2002. p.180). Hinds (1990) suggested the same idea. Hinds did research on expository writing in Japanese, Chinese, Korean and Thai. He claimed that Oriental writers used the inductive approach. English speaking people prefer deductive writing (Noor, 2001, p.261).

In Chinese writing, students would like to start with the explanation of conditions. After clearing the surroundings, the Chinese students get to the real target. As a Chinese I have the same feeling, before talking about the real target I would like to use some words to explain why, how and when my work should begin. By using analysis and critique of other's study I will show my claim indirectly and later in the article. That is the reason why some English-speaking people have difficulty finding the clear claim within an academic article written by a Chinese writer.

\section{Differences in reader's and writer's responsibility}

It is considered that there is a great diversity of reader and writer responsibility in academic writing. By giving examples from Japanese texts and anecdotes of conversations between Americans and Japanese, Hinds (1987) suggests that "English use a writer responsible rhetoric, Japanese use a reader responsible rhetoric". (Hinds, 1987, cited in Noor, 2001, p.263) That is to say in English academic writing it is the writer's responsibility to make the article easy to read. Furthermore, in the process of writing the writer should be aware of the audience, which can link to Johns' (1993) viewpoint. In contrast, In Japanese writing, it is the reader's responsibility to understand the author's intention for writing the article. Hinds (1990) said that the two kinds of rhetoric fulfill different expectations of the reader.

Clyne (cited in Noor 2001, p.263) also brings forward similar claims for English and German. Clyne thinks that the writer should afford the burden to make their articles easy to read in English-speaking countries. While in German-speaking countries "the reader has to make the extra effort to understand the text."(Clyne 1987 cited in Noor 2001, p.263). In the German tradition of academic writing the author would like to provide more knowledge and theory beside the main point for the reader. The German way of writing is "not designed to be easy to read." (Clyne 1987, cited in Noor 2001, p.263) That is to say, German writing is to give readers stimulus to think instead of telling them directly. Therefore German writing is not easy to read and it needs readers to make more effort.

Hinds (1987) compares classic Chinese and modern Chinese with Japanese and English (cited in Noor, 2001, p.262). Classic Chinese is more like Japanese. The language marks in texts can be absent or less and the transition sentences are less so that readers have to be active to understand the writing. English is writer-responsible rhetoric. Modern Chinese is more like English. The discourse needs to be directly presented to readers and try to persuade readers to believe what the writer says.

\section{Differences in the attitude toward quotation}

Differences in academic writing also lie in the attitudes toward quotation. Chinese writers are fond of using quotations and allusions because they are familiar, and love, their history and literature of past ages. In 1950-1970 Chinese writers liked to quote chairman Mao's words to make their claims become more persuasive. In modern Chinese writing, people also like using quotations. They may use proverbs such as "A lazy youth, a lousy age" from Kongzi, the founder of Confucianism to persuade the youth who do not work hard. English writers do not use this approach, and Anglo-American English rhetoric does not consider quotations from authorities as a proper way of expressing ideas. The English people tend to express their claims directly by using voice, such as I. What is worth mentioning is that when English writers cite some person's viewpoint to support their own claim, they find some evidence to explain why it is worth quoting, and show how the quotations helps express the author's claim.

\section{Differences in the attitudes on good writing}


Different culture made the standard of good writing is widely divergent. It can result in the diversity in academic writings. listed the different criteria on good writing between Chinese and American composition teacher. In the view of Chinese composition teachers a good article should not only brought forward valuable but also need to disseminate accepted morality of society. Chinese writer consider (disseminate morality) in their article as part of their duties. But in English composition teachers have no right to deal with issues of morality. Li also suggests that "imitation is acceptable", that is to say in China, when students are learning about how to write an academic article imitate other's work is acceptable. But in America is forbidden, a good writing should show the author's "unique voice" or particular viewpoint. It is worth mentioning that expressing personal emotion is a good sign in Chinese writing. It can show the author's enthusiasm in the certain academic writing and helps readers to understand or feel the author's claim deeply. For English writing, bringing too much emotion in writing is not good. American or English writers think that emotion should not appear too much in Academic writing. Emotion is not an essential part of writing. Expressing personal emotion too much in academic writing can mislead the readers. That is to say, readers can not easily grasp the writer's claim beside too many emotions.

\section{Difference in writing conventions of discourse community}

As a part embedded in the cultural background, the discourse community plays an important role in academic writing. The differences in social conventions of discourse community influence people's academic writing a lot, according to the studies of Flowerdew (2000), Kennedy (2001) and Spack (1997). In their studies, they give many examples to prove that there are many significant differences in academic writing between L1 and L2. The example of Japanese student Yuko's experience mentioned by Spack (1997) shows some detailed significant differences in academic writing in different discourse communities embedded in cultures. She met lots of troubles in academic writing because she did not know the conventions in US academic writing discourse community. That is to say, knowing the different conventions in different discourse communities is important in academic writing. These differences exist in the reality and they are not overstated.

\section{CONCLUSION}

Since the first contrastive rhetoric study by Kaplan in 1966, many studies have been produced, and over several decades of development, there have been many contributions gained from previous contrastive rhetoric studies. However, there are still some limitations and weak points in this area. So some researchers summarized and made critiques about certain studies. Stapleton (2002) claims the differences between academic writing in an L1 and an L2 are often misrepresented and overstated. I disagree with Stapleton. I believe that there are differences between academic writing in L1 and L2, and they are not overstated. Results of many studies support my argument that there do exist differences between academic writing in L1 and L2 in various aspects and they are not overstated. In this article, many kinds of differences existing in L1 and L2 academic writing have been discussed. These differences are mainly in three parts as following: differences in the level of lexicon, differences in the level of sentence, and differences in the level of passage. At the level of lexicon, the differences in the formation of word and in the choice of word have been mentioned. Then at the level of sentence, the differences in the sentence patterns and in the sentence subject have been discussed. Finally at the level of passage, differences in the choice of writing topic, in the voice, in the organization, in the reader's and writer's responsibility, in the attitude toward quotation, in the attitude on good writing, and in writing conventions of discourse community have been elaborated. However, in order to get more evidence for my point of view and make the statement more powerful, more contrastive rhetoric studies are needed. Besides, one point worths our further consideration, that is, languages are alive and dynamic; and the languages will change with many factors such as time, cross-cultural communication, etc. So the differences between academic writing in L1 and L2 also can change. The dynamic point of view could push contrastive rhetoric studies to go further and wider and then help people understand each other better in the cross-cultural communication.

\section{REFERENCES}

[1] Connor, U. (1996). Contrastive rhetoric: Cross cultural aspects of second language writing. Cambridge: Cambridge University Press.

[2] Flowerdew, J. (2000). Discourse community, legitimate peripheral participation, and the nonnative-English-speaking scholar. TESOL Quarterly, 34, 127-150

[3] He, Shanfen. (2002). Contrastive studies of English and Chinese languages. Shanghai: Shanghai Foreign Language Education press.

[4] Kennedy, C. (2001). Language use, language planning and EAP. In J. Flowerdew \& M. Peacock (Eds), Research perspectives on English for academic purposes (p.25-41). Cambridge: Cambridge University Press.

[5] Matsuda, P. K. (1997). Contrastive rhetoric in context: A dynamic model of L2 writing. Journal of Second Language Writing, 6 (1), 45-60.

[6] Mohan, B.A. \& Lo, W.A. (1985). Academic writing and Chinese students: Transfer and developmental factors. TESOL Quarterly, 19, 515-534.

[7] Noor, R. (2001).contrastive rhetoric in expository prose: Approaches and achievements. Journal of Pragmatics, 33, $255-269$.

[8] Pan, Wenguo. (1997). The outline of Contrastive studies of English and Chinese languages. Beijing: Beijing Language and Culture Press. 
[9] Spack, R. (1997) The acquisition of academic literacy in a second language. A longitudinal case study. Written Communication, $14,3-62$

[10] Stapleton, P. (2002). Critiquing voice as a viable pedagogical tool in L2 writing: Returning the spotlight to ideas. Journal of Second Language Writing, 11, 177-190.

[11] Xiaoping, Ao. (1997). General views on Chinese language and Chinese words. Retrieved October 20, 2010 from http://www.cnd.org/HXWZ/CM97/cm9707b.hz8.html

[12] Xiufeng, Zhao. (2004). Structural Differences of Nominal Groups Between English and Chinese and Its Influence on Chinese Students' Style in English Writing--A Positivist Research. Journal of Foreign Language Education 2004.25 (6) 55-57

Yingli Wang was born in Tangshan, China in 1981. She received his M.A. degree in English Education from Waikato University, New Zealand in 2006.

She is currently a lecturer in the School of Foreign Languages, Hebei United University, Hebei, China. Her research interests include English teaching and linguistics. 